\title{
PENGARUH PERUBAHAN MIKROSTRUKTUR TERHADAP PERUBAHAN KEKERASAN RADIANT TUBE YANG TELAH BEROPERASI SEJAK 2003
}

\section{MICROSTRUCTURE CHANGE EFFECT OF VIOLENCE AGAINST RADIANT TUBE THAT HAS BEEN OPERATING SINCE 2003}

\author{
Laili Novita Sari ST, MT ,Sutarjo ST, MM \\ Balai Besar Teknologi Kekuatan Struktur - BPPT \\ Kawasan PUSPIPTEK Gedung 220 Serpong, Tangerang Selatan \\ e-mail: laili.novita@gmail.com
}

\begin{abstract}
Abstrak
B2TKS - Sub Bidang Analisa Kerusakan dan umur sisa telah melakukan Remaining Life Assesment pada radiant tube pada perusahaan minyak dan gas bumi dari tahun 2003 - 2016. Dalam penentuan RLAdigunakan grafik dari Era Teknologi dimana penentuannya berdasarkan perubahan struktur mikro sedangkan untuk perubahan kekerasan material belum ada literatur atau penelitianyang menunjukkan tentang perubahan kekerasan pada material ASTM A 213 T5yang terjadi selama proses penuaan. Karena itu dilakukan perumusanperubahan kekerasan terhadap speriodisasi pada tube radiant material ASTM A 213 T5. Dengan mengetahui penurunan kekerasan yang wajar terhadap speriodisasi diharapkan akan mempermudah pendeteksian awal kondisi abnornal atau kerusakan. Berdasarkan pengamatan metalografi dan uji kekerasan diketahui bahwa penurunan kekerasan terjadi secara proporsional dengan peningkatan prosentase spriodisasi. Klasifikasi $A, B, C$ penurunan kekerasan dibawah 0,7 HB/HBO sedangkan klasifikasi $D$ sampai berikutnya penurunan kekerasan diatas $0,7 \mathrm{HB} / \mathrm{HBO}$.
\end{abstract}

Kata Kunci : Kekerasan, radiant tube, in situ metalografi, ASTM A 213 T5

\begin{abstract}
B2TKS - Sub-Analysis of Damage and residual life has done Remaining Life Assessment to the radiant tube on oil and gas companies from 2003 - 2016. In determining the RLA, it was used graph of the Era Technology where the determination is based on the microstructural changes while there are no literature or research which shows the hardness changing of material ASTM A 213 T5 which occurs during the aging process. Therefore it need to make formulation about the changes of spheriodizationto the chages of hardness of radiant tube material ASTM A 213 T5. By knowing a reasonable decrease in hardness to spheriodization, it was expected to detect the abnormal condition or damage earlier. Based on the examination of metallographic and hardness testing, is was known that the reduction of hardness occur in proportion to the increase ofsperiodization percentage. In spheriodzation changing of Classification A, B, C the decrease of hardness below $0.7 \mathrm{HB} / \mathrm{HBO}$ while classification $\mathrm{D}$ until the next classification, reduction of hardness above 0,7HB / HBO.
\end{abstract}

Keyword : hardness, radiant tube, in situ metallography, ASTM A 213 T5

\section{PENDAHULUAN}

Pada saat ini, kebanyakan peralatan perusahaan minyak dan gas bumi di Indonesia telah beroperasi diatas 25 tahun bahkan ada yang mencapai 30 tahun. Tentu saja kondisi dan kemampuan beroperasi dari peralatan tersebut perlu diselidiki. Selain demi keselamatan dan keamanan juga demi memotong biaya pembangunan kembali peralatan. Proses remaining life assesmentperlu dilakukan untuk mengetahui sisa umur dari material.

Berbagai metode Remaining life assessment telah digunakan antara lain dengan metode ultra sonic, replika dan uji kekerasan bahkan ada yang sedang mengembangkan alat uji potensial drop monitoring seperti yang dilakukan oleh Joseph Corcoran dalam disertasinya yang berjudul Creep monitoring using installed potensial drop sensors [1]. 
Karena kondisi dilapangan dan di laboratorium memiliki kondisi stress yang berbeda yang akan mempengaruhi potensial pengukuran maka peralatan ini belum siap digunakan secara riil. Telah dilakukan pengukuran umur sisa dengan menggunakan metode impressed creep test [2] akan tetapi dalam aplikasinya selain tidak bisa digunakan dilapangan tetapi juga karena alat ini sangat sensitif sehingga tegangan displacement kecil terdeteksi sebagai hasil pengukuran yang menyebabkan hasil pengujian berbeda dengan uniaxial test. Untuk mempermudah proses remaining life assessment juga telah dilakukan iterasi dengan menggunakan rumus Larson Miller dan rumus creep lain [3] akan tetapi tidak berhasil karena pada kenyataannya bahwa material pada saat operasi tidak mengalami pembebanan yang sama tetapi berfluktuasi maka hasil iterasi ini tidak dapat digunakan secara riil. Sampai saat ini metode remaining life assessment yang paling tepat adalah tehnik replika dengan catatan adanya pembanding material yang masih baru [4]. Meskipun demikian tehnik replika mempunyai kekurangan antara lain hanya bisa mendeteksi dilokasi tertentu dan dipermukaan. Selain itu penilaian dari inspektor dan metode pengambilan sampel berpengaruh terhadap hasil klasifikasi. Seperti yang pernah dilakukan oleh EPRI yang melakukan percobaan round robin dimana beberapa inspektor yang berbeda melakukan penilaian pada replika yang sama [5]. Tampak bahwa inspektor yang berbeda menghasilkan interpretasi yang berbeda pada replika yang sama seperti terlihat pada grafik berikut :

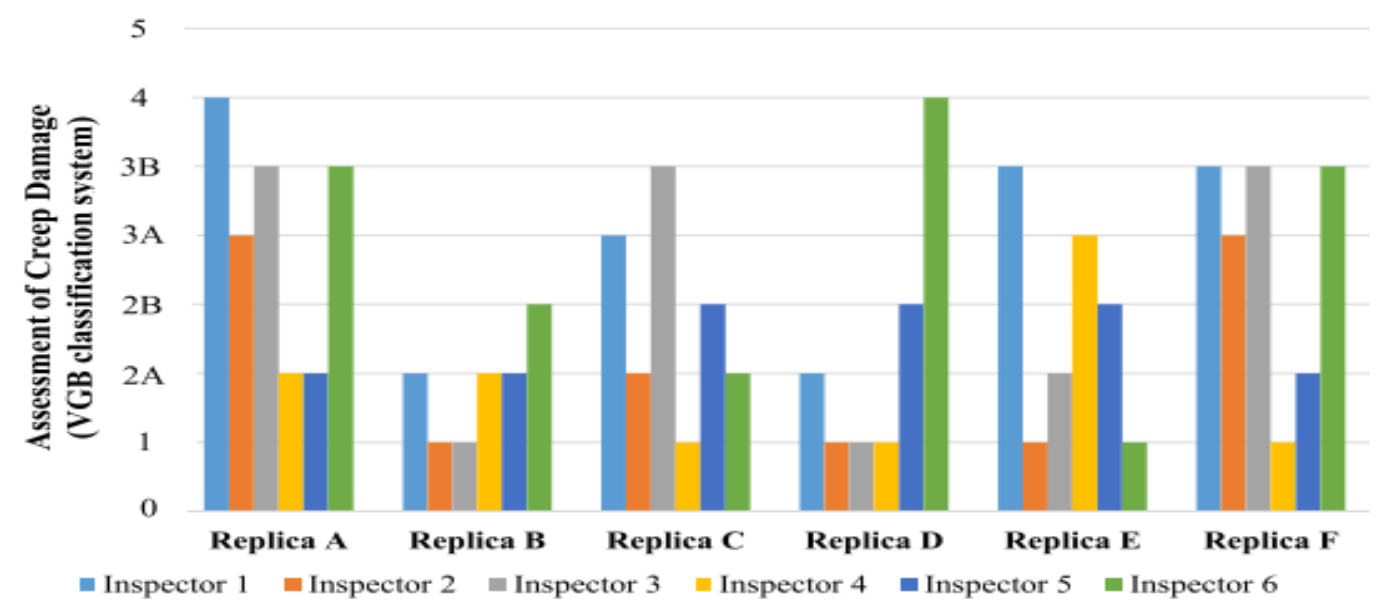

Gambar 1 : Hasil Round robin test diadakan oleh EPRI [5]. Enam replika diinterpretasikan atau dinilai oleh enam perusahaan yang berbeda dan diminta untuk mengklasifikasikan kerusakan menggunakan sistem klasifikasi VGB pada tabel 1. Range yang sangat lebar menunjukkan bahwa perbedaan interpretasi yang sangat besar terhadap hasil replika.

Tabel 1. VGB criteria berdasarkan status pemisahan batas butir [6]

\begin{tabular}{cl}
\hline Assessment Class & Structural and and Damage Conditions \\
\hline 0 & As received, without thermal service load. \\
\hline 1 & Creep exposed, without cavities \\
\hline $2 \mathrm{~A}$ & $\begin{array}{l}\text { Advanced creep exposure, numerous cavities without } \\
\text { preferred orientation. }\end{array}$ \\
\hline 2B & $\begin{array}{l}\text { More Advanced creep exposure, numerous cavities } \\
\text { without preffered orientation. }\end{array}$ \\
\hline 3A & Creep damage, numerous oriented cavities \\
\hline 4 & $\begin{array}{l}\text { Advance creep damage, chains of cavities and/ or grain } \\
\text { boundary separations. }\end{array}$ \\
\hline 5 & Advanced creep damage, microcracks. \\
\hline
\end{tabular}


Berdasarkan penelitian Kavita [7] terdapat korelasi antara hardness dan diagram larson miller akan tetapi hanya untuk material ASTM A 387 grade 91 [8]. Selain itu juga dilakukan pada inconel alloy 740 [9]. Setiap material memiliki prilaku korelasi kekerasan dan perubahan struktur mikro yang berbeda seperti juga yang dilakukan Sukegawa dan kawan - kawan yang menentukan korelasi antara creep dengan kekerasan pada material SS 304 [10] menghasilkan korelasi berbeda dengan hasil penelitian Kirikara dan kawan - kawan yang melakukan penelitian tentang korelasi struktur mikro dengan kekerasan pada material SS 321 [11].

Baja karbon, baja Cr-Mo, dan baja tahan karat austenitik merupakan material yang biasa dugunakan untuk pipa. Baja karbon terbatas pada aplikasi suhu rendah. Banyak perusahaan memilih untuk membatasi baja karbon untuk aplikasi di bawah $427^{\circ} \mathrm{C}$ untuk mencegah masalah dari speriodisasi dan grafitisasi. Penambahan kromium (Cr) dan molibdenum (Mo) meningkatkan kekuatan suhu tinggi, ketahanan terhadap spheroidisasi, dan ketahanan terhadap oksidasi dan beberapa mekanisme korosi. Baja tahan karat austenitik sering digunakan untuk aplikasi pipa di mana suhu melebihi sekitar $704^{\circ} \mathrm{C}$ atau ketahanan korosi yang dibutuhkan dalam proses [12].

Bahan pipa pada umumnya, sesuai ASTM atau spesifikasi pipa, dan batas suhu desain logam maksimum API Std. 530 tercantum dalam Tabel 1.

Dalam makalah ini telah dilakukan penelitian tentang penurunan kondisi struktur mikro dengan hasil uji kekerasan pada material ASTM A 213 T5. Material ini merupakan material yang sering digunakan untuk boiler atau heater pada perusahaan pengolaan minyak dan gas di Indonesia.Material Ini merupakan material yang disyaratkan dalam API 530. Material ASTM A 213 T5 merupakan mateial dengan struktur mikro feritbainit. Berdasarkan penelitian Kavita [7] material ferrit pearlit mengalami perubahan dan berpengaruh pada kuat luluh, pengurangan luasan, kuat impak dan kekerasan.

Tabel 2. Material yang umum digunakan untuk tube heater [12]

\begin{tabular}{|c|c|c|c|}
\hline Material & $\begin{array}{l}\text { Seamless Tube } \\
\text { Specification }\end{array}$ & $\begin{array}{l}\text { Seamless Pipe } \\
\text { Specification }\end{array}$ & $\begin{array}{c}\text { Design Metal } \\
\text { Temperature } \\
\text { Limit per API } \\
\text { RP530 }\end{array}$ \\
\hline Carbon Steel & A53 & A106 & $540^{\circ} \mathrm{C}$ \\
\hline $1 \frac{1}{4} \mathrm{Cr}-1 / 2 \mathrm{Mo}$ & A213 T11 & A335 P11 & $595^{\circ} \mathrm{C}$ \\
\hline $21 / 4 \mathrm{Cr}-1 \mathrm{Mo}$ & A213 T22 & A335 P22 & $650^{\circ} \mathrm{C}$ \\
\hline $3 \mathrm{Cr}-1 \mathrm{Mo}$ & A213 T21 & A213 P21 & $650^{\circ} \mathrm{C}$ \\
\hline $5 \mathrm{Cr}-1 / 2 \mathrm{Mo}$ & A213 T5 & A335 P5 & $650^{\circ} \mathrm{C}$ \\
\hline $5 \mathrm{Cr}-1 / 2 \mathrm{Mo}-\mathrm{Si}$ & A213 T5b & A335 P5b & $705^{\circ} \mathrm{C}$ \\
\hline $9 \mathrm{Cr}-1 \mathrm{Mo}$ & A213 T9 & A335 P9 & $705^{\circ} \mathrm{C}$ \\
\hline 9Cr-1Mo-V & A213 T91 & A335 P91 & $650^{\circ} \mathrm{C}^{1}$ \\
\hline Type 304H & A213 TP304H & A312 TP304H & $540^{\circ} \mathrm{C}$ \\
\hline Type 316 & A213 TP316 & A312 TP316 & $540^{\circ} \mathrm{C}$ \\
\hline Type 321 & A213 TP321 & A312 TP321 & $540^{\circ} \mathrm{C}$ \\
\hline Type 347 & A213 TP347 & A312 TP347 & $540^{\circ} \mathrm{C}$ \\
\hline Alloy $800 \mathrm{H} / 800 \mathrm{HT}$ & B407 Gr 800H/800HT & B407 B407 Gr 800H/800HT & $985^{\circ} \mathrm{C}^{1}$ \\
\hline HK & A608 Gr HK40 ${ }^{2}$ & ** A351 HK-40 & $1010^{\circ} \mathrm{C}^{1}$ \\
\hline HP & $* *$ & A297 HP & $* *$ \\
\hline
\end{tabular}

Notes: $\quad 1$. These materials are commonly used for heater tubes at higher temperatures in applications where the internal pressure is so low that rupture strength does not govern the design.

2. Centrifugally cast pipe.

\section{BAHAN DAN METODE}

\section{Bahan dan data teknis :}

Radian tube Material : ASTM A 213 T5 ini beroperasi mulai dari tahun 1981 sampai dengan hari ini. Beroperasi pada Suhu dibawah $500{ }^{\circ} \mathrm{C}$
Dalam makalah ini dilakukan penyelidikan menggunakan dua metode :

- Metalografi

Metode ini berfungsi untuk memgetahui tingkat speriodisasi material dan jumlah bainit yang terkadung. 
- Uji kekerasan menggunakan metode leed.

Metode ini merupakan metode paling praktis karena tidak meninggalkan jejak yang dalam serta mudah dibawah. Alat ini digunakan karena dalam pemeriksaan berkala yang peralatan terpasang pada unit.

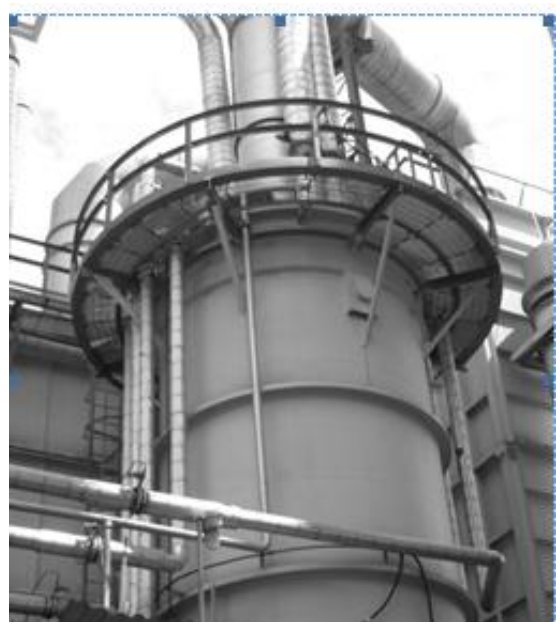

Gambar 2 : Dapur F 101 dari luar

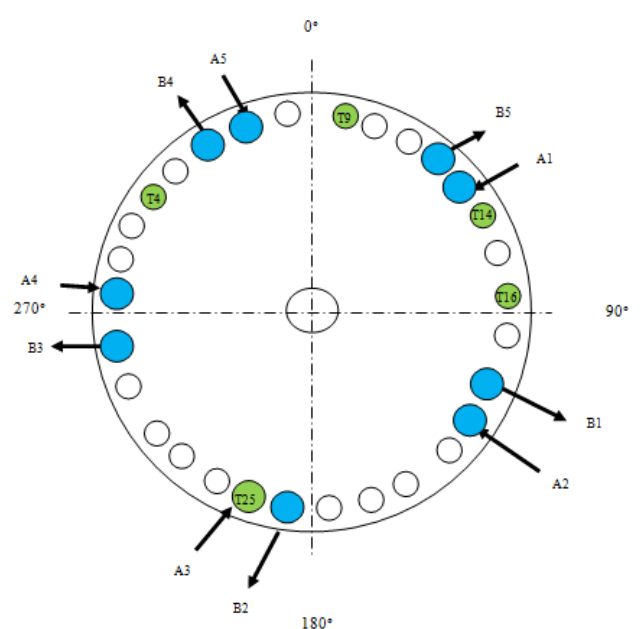

Gambar 3 : Skema bagian dalam

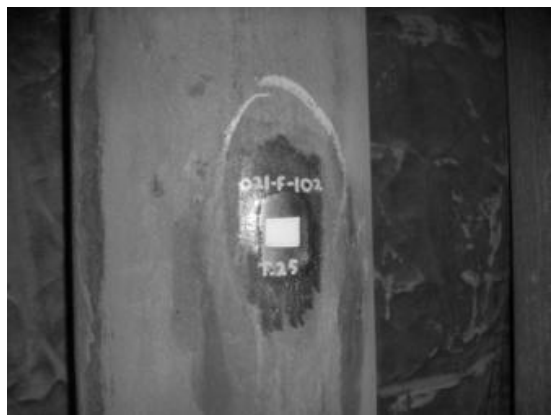

Gambar 4 : Salah satu pipa radiant tube yang diperiksa

\section{HASIL DAN PEMBAHASAN}

Material ASTM A 213 T5 merupakan material dengan struktur mikro berupa ferrit bainit. Tidak seperti ferite perlit secara normal perlit akan terlihat jelas sedangkan bainite terlihat kurang jelas Hasil pengambilan replika pada reformer yang diperiksa selama lebih dari 10 tahun menunjukkan hasil klasifikasi material pada Klas D. Penentuan klasifikasi berdasarkan Era Teknologi pada tabel 3 [13].

Gambar 5 menunjukkan salah satu hasil metode in situ metalografi atau replika yang menunjukkan kondisi klasifikasi A dimana bainite masih utuh belum terjadi speriodisasi. Kondisi ini hampir dikatakan berada pada kondisi struktur mikro material baru.

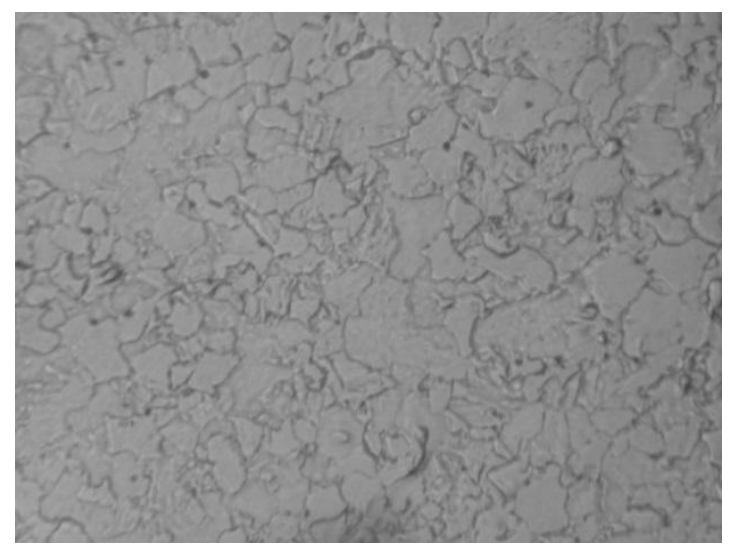

Gambar 5: Struktur mikro berupa ferite bainit klasifikasi A

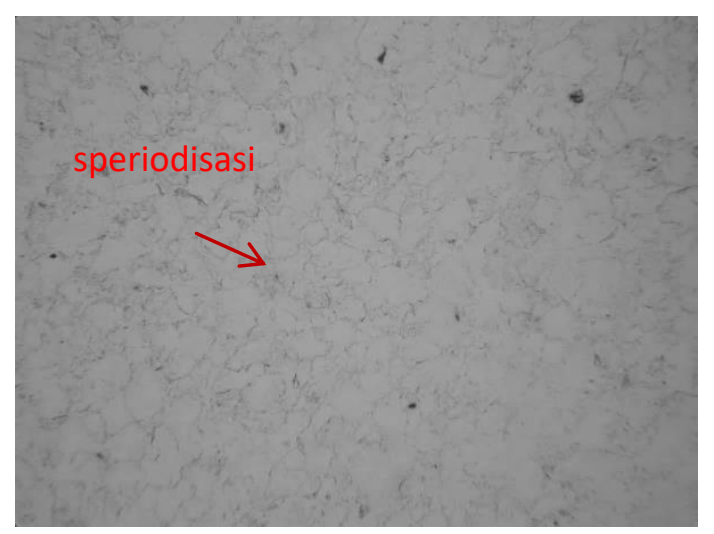

Gambar 6 : Berupa feritik dengan speriodisasi tingkat awal, klasifikasi B.

Gambar 6 menunjukkan bahwa bainite mulai tersperiodisasi tingkat awal dimana speriodisasi masih berada pada butir dan speriodisasi baru terjadi dibawah $20 \%$. 


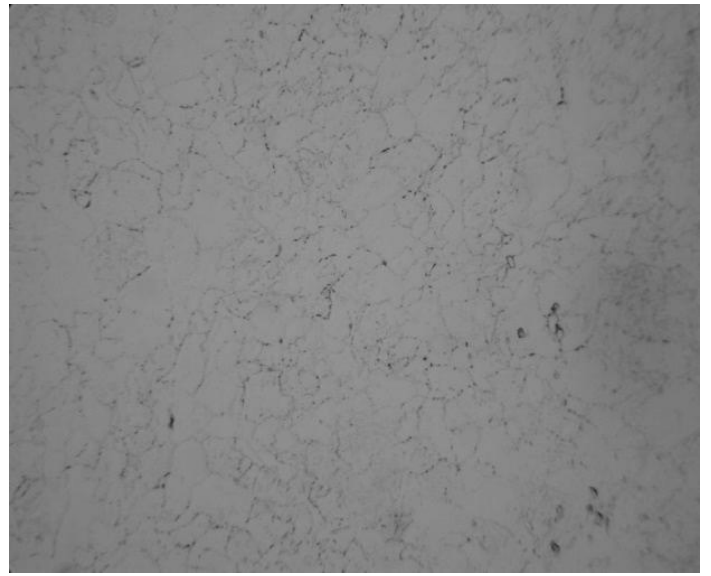

Gambar 7 : Berupa feritik dengan speriodisasi tingkat menengah, klasifikasi C.

Spriodisasi tingkat menengah adalah lamellar $\mathrm{Fe}_{3} \mathrm{C}$ sudah berupa globular akan tetapi masih beberapa yang berbentuk lamellar. Proses speriodisasi baru mencapai $20-40 \%$ [13].

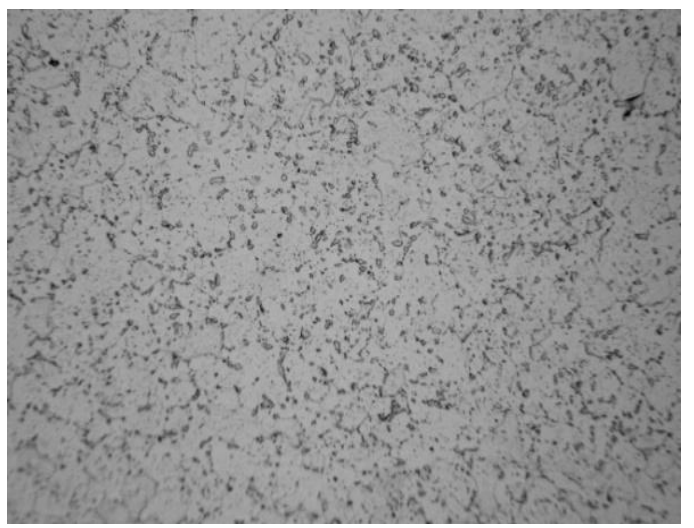

Gambar 8 : Berupa feritik dengan speriodisasi karbida menyebar merata, klasifikasi D.

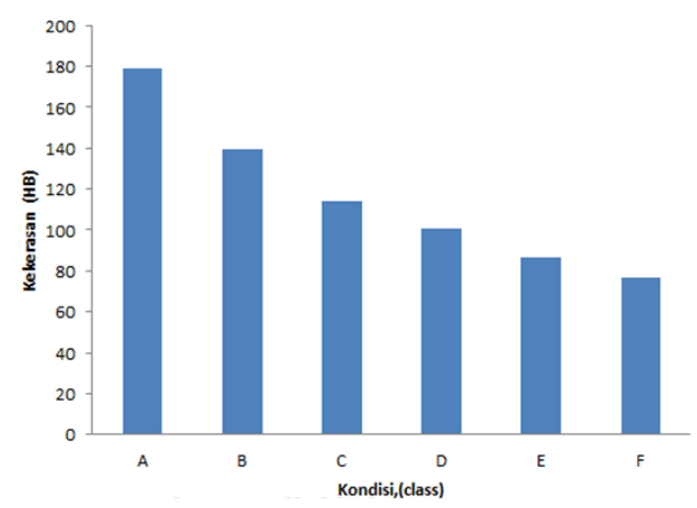

Gambar 9 : Nilai kekerasan terhadap class speriodisasi.
Dengan menghubungkan kondisi klasifikasi struktur mikro dan hasil uji kekerasan pada beberapa sampel maka diperoleh grafik seperti pada gambar 9 .

Gambar 9 menunjukkan hubungan penurunan kekerasan terhadap klasifikasi speriodisasi. Untuk kondisi $\mathrm{E}$ dan $\mathrm{F}$ merupakan hasil prediksi dari pola kurva yang terjadi pada class A, B, C dan D karena belum pernah dilakukannya pengujian pada material pada klasifikasi $\mathrm{E}$ dan $\mathrm{F}$. Korelasi menunjukkan bahwa material mengalami penurunan kekerasan seiring terjadinya speriodisasi. Penurunan kekerasan terjadi karena karbida yang berbentuk lamellar menjadi globular yang mengurangi hambatan dalam pergerakan dislokasi.

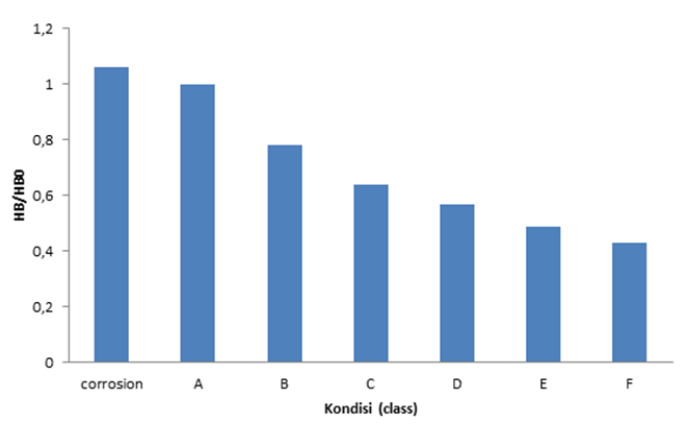

Gambar 10 : HB/HB0 terhadap kondisi speriodisasi.

Dalam gambar 10menunjukkan hubungan penurunan kekerasan dalam perbandingan kekerasan terukur dengan kekerasan standar HB/HBO terhadap klasifikasi speriodisasi.Seperti juga yang dijelaskan sebelumnya bahwa kondisi class $\mathrm{E}$ dan $\mathrm{F}$ merupakan hasil prediksi dari kurva sebelumnya. Pada material yang terkorosi belum dipastikan mengalami perubahan kekerasan karena itu perlu diadakan pembahasan khusus. Beberapa jenis korosi bisa mengakibatkan penurunan kekerasan sejak awal tetapi beberapa jenis korosi tidak dapat diketahui penurunan kekerasannya sejak awal. 
Tabel 3. Tabel Era Teknologi [13]

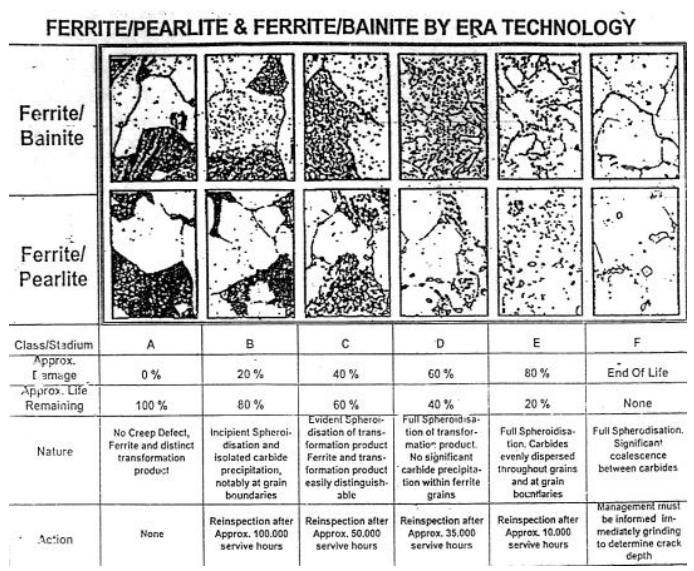

\section{KESIMPULAN}

Berdasarkan uji in situ metalografi dan in situ kekerasan yang telah dilakukan pada beberapa pipa dapur pengolahan minyak selama beberapa periode TA pada material ASTM A 213 T5 menunjukkan bahwa penurunan kekerasan terjadi proportional terhadap prosentase perubahan struktur mikro berupa speriodisasi.Kondisi klasifikasi terburuk yang pernah diamati yaitu class $D$ menunjukkan penurunan kekerasan dibawah 0,7HB/HB0.Untuk kondisi class $E$ dan $\mathrm{F}$ serta material korosi perlu dilakukan uji laboratorium lebih lanjut.

\section{DAFTAR PUSTAKA}

1. Corcoran. Joseph. "Creep monitoring using permanently installed potensial drop sensors", Thesis for the degree on doctor of philosophy, imperial college london, Agustus 2015.

2. Larsson, Jonas. "Evaluation of current methods for creep analysis and impression creep testing of power plant steel", Thesis for the degree on master, KTH royal institute of technology . 11 Oktober 2012.

3. Seng. Edwin Lim Chui,"Evaluation of high temperature boiler tube using iterative analytical approach", thesis for the bachelor degree, Universiti Teuku abdul rahman, Malaysia, April 2013.

4. Sahu, dwarka prasad."The remaining life assessment of high temperature services exposed component by metallographic thechnique", Brno, Czech Republic, 2014.

5. Parker, J. D, "Review of the application of metallurgical Replicas to detection of component damage", component matters, EPRI, 2014 b.

6. VGB- kraftwerkstechik GmbH, VGB, TW 507,"Guideline for assessment of microstructure and damage development of creep exposed materials for pipes and boiler component. Esson. 1992.

7. Kavita Sakhala et. al "Study of microstructure degradation of boiler tubes due to creep for remaining life analysis", International journal of engineering research and application, vol 4, Issue 7 (version 2), PP 93 -99. July 2014

8. Furtado, H.C.,L.H Almaeda, L Le May “ Damage and remaining life estimation in high temperature plant with various operation condition, OMMI, Vol. 5, Issue I, May 2008.

9. Bachetti, Daniel Henry " Microstructural evaluation and creep rupture behaviour inconel alloy $740 \mathrm{H}$ fusion weld", Thesis for master degree, Lehigh University, January 2013.

10. Sekegawa. Masayuki,et. al "Fudamental study on Non Destructive Detection of creep damage for $18 \mathrm{Cr}$ 8Ni (SUS 304) steel", Hitachi Research Laboratory ,1983.

11. Kirikara. Seishin et al,"Fudamental study on Non destructive Detection of Creep damage for Austenitic stainless steel, Hitachi Research Laboratory, 1983.

12. API third Edition 2010.

13. Era Teknologi. 